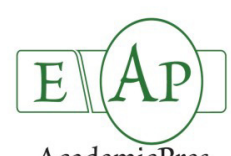

AcademicPres

\title{
Phenolic Profile and Antioxidant Activity of Pulp and Peel from Peach and Nectarine Fruits
}

\author{
Branka T. STOJANOVIC ${ }^{1}$, Snezana S. MITIC ${ }^{1}$, Gordana S. STOJANOVIC ${ }^{1}$, Milan N. \\ MITIC $^{1}$, Danijela A. KOSTIC ${ }^{1}$, Dusan Dj. PAUNOVIC ${ }^{1}$, Biljana B. ARSIC ${ }^{2 *}$ \\ ${ }^{1}$ University of Niš, Faculty ofSciences and Mathematics,Department ofChemistry,Višegradska33,P.O.Box224, 18000Nis,Republic ofSerbia; brankastojanovic81@gmailcom; \\ mitich_s@yahoo.com;stgocaus@yahoo.com;milanmitic83@yahoo.com;danijelaaakostic@yahoo.com;dpaunovic3@gmail.com \\ ${ }^{2}$ University of Niš Faculty of Sciences and Mathematic, Department of Mathematics, Višegradska33, P. O. Box 224, 18000 Niš, \\ RepublicofSerbia;ba432@ymail.com (*orrespondingauthor)
}

\begin{abstract}
Peach (Prunus persica L.) is a fruit of high nutritional and economic value. Carbohydrates, dietary fibers, minerals and organic acids are among the major constituents of peach fruit, which contribute to the nutritional quality of both fresh fruits and juice. Polyphenolic compounds found in peach may play an important role in physiological functions related to human health. Different polyphenolics may have varied biological activities including antioxidant activity. In this study antioxidant characteristics between peel and pulp of different peach cultivars ('Radmilovčanka', 'June Gold', 'Blake', 'Hale', 'Vesna', 'Adria') and one of nectarine ('Fantasia') were investigated. The peel and pulp extracts showed a huge amount of total phenolics (TP), total flavonoids (TF), total hydroxycinnamates (TH) and total flavonols (TFL), ranging from 42.7-211.4, 11.1-128.5 mg GAE/100 g fresh weight (f.w.) (TP), 21.9-94.9, 5.0-58.9 mg CE/100 g f.w. (TF), 28.4-389.2, 8.5-165.8 $\mathrm{mg} \mathrm{kg}^{-1}$ f.w. (TH) and 17.3-54 mg kg ${ }^{-1}$ f.w. (TFL). High contents of phenolic compounds were significantly correlated with high antioxidant capacities. Peach pulp and peel differ significantly in their phenolic profiles: the pulp contains mainly chlorogenic, neochlorogenic and $p$-coumaric acids, whereas the peel possesses chlorogenic, neochlorogenic and $p$-coumaric acids together with several flavonol glycosides in huge amounts. Our results indicate that cultivar and extraction solvent play important roles in phenolic compositions and antioxidant properties of peach and nectarine extracts, which was shown using statistical analysis (ANOVA). There are high correlations between extracted phenolic compounds and peach and nectarine cultivars, and used solvent and part of the fruit (peel and pulp).
\end{abstract}

Keywords: chlorogenic acid, extracts, glycosides, HPLC, statistics

\section{Introduction}

Traditional fruits and vegetables possess numerous healthy properties. The positive influence of these natural products is attributed to their bioactive compounds: dietary fiber and antioxidants, mainly phenolic compounds, flavonoids, phenolic acids (Gorinstein et al., 2002; Alothman et al., 2009). As it has been shown, diets rich in dietary fiber and other bioactive substances have decreased the risk of diseases such as coronary atherosclerosis, obesity and cancer (Rimm et al., 1996). It is well known that phenolic compounds possess antioxidant properties and prevent the oxidation of low density lipoprotein cholesterol (LDL-C) (Silva et al.,2002).

Phenolic compounds constitute a large and heterogeneous class of compounds. Within each plant species, the nature of those compounds can vary from organ to organ but is constant. These factors have been used, in recent years, in the characterization of several food products of plant origin by their phenolic profile. Factors contributing to the variability in phenolic distribution include cultivar and genetic origin, maturity, climate, position of tree, and agricultural practices (Witzum and Steinberg, 1991).

Moreover, contents of organic acids, carbohydrates and phenolics are not uniformly distributed within different parts of fruits, and most of them are concentrated in the epidermal and subepidermal layers of fruits (Mattila et al., 2006; Manzoor et al.,2012a).

Peach (Prunus persica L.) fruit have high economic and nutritional value (Manzoor et al., 2012b). Carbohydrates, organic acids, minerals and dietary fibers are among the major constituents of peach fruit, which contribute to the nutritional quality of both fresh fruits and juice.

The critical point in studying polyphenols in plant materials is the used extraction procedure since it dictates the nature and quantity of polyphenols that will be transferred into the extract and 
176

further characterized (Kajdžanoska et al., 2011). Various solvent systems have been used for the extraction of polyphenols from plant materials. Water and aqueous mixture of ethanol (Gorinstein $e t$ al., 2002), methanol (Orazem et al., 2011; Manzoor et al., 2012a) and acetone (Hamauzu et al.,2006) are commonly used. Alothman et al. (2009) reported that aqueous acetone was superior to methanol and ethanol in the extraction of phenols from fruits.

Recently, the investigation on peach from Serbia (Mitic et al., 2013) was performed using the combination of methanol and $\mathrm{HCl}$ for the extraction of polyphenolic compounds, and not separating pulp from peel.

The objective of this study was to determine the polyphenol profile and antioxidant capacity of peel and pulp of six different peach cultivars and one nectarine cultivar, and to examine the efficiency of different $\mathrm{HCl}$ concentrations in $80 \%$ acetone $(\mathrm{v} / \mathrm{v})$ for the extraction of polyphenolic compounds.

\section{Materials and Methods}

\section{Fruitsamples}

Six different peach cultivars ('Radmilovčanka', 'June Gold', 'Blake, 'Hale,' 'Vesna' and 'Adria') and one of nectarine ('Fantasia') were picked in the phase of commercial maturity during 2013 harvest season in southern Serbia, and stored at $-20^{\circ} \mathrm{C}$. Prior to analysis, peaches were defrosted, pilled and mixed in the kitchen blender.

\section{Chemicals}

Standards of gallic, $p$-coumaric, chlorogenic acid, quercetin and kaempferol-3-glucoside were purchased from Sigma-Aldrich (St. Louis, MO, USA). Trolox (6-hydroxy-2,5,7,8tetramethylchroman-2-carboxylic acid), Iron(II)sulphate, 2,4,6tri(2-pyridyl)-s-triazine (TPTZ), 2,2'-azinobis(3ethylbenzothiazoline-6-sulfonic acid (ABTS), 2,2'-diphenyl-1picrylhydrazil (DPPH), Folin-Ciocalteau's reagent, and catechin were obtained from Fluka (United Kingdom). Deionized water was used for the preparation of all solutions, and it was produced using MicroMed high purity water systems (TKA Wasseraufberei tungssystem $\mathrm{GmbH}$ ).

\section{Extraction of phenolics}

The polyphenolic compounds from fruits (both pulp and peel) samples were extracted using conventional solvent extraction procedure. Ten grams of homogenized samples were extracted in an ultrasound bath with $30 \mathrm{ml}$ of $80 \%$ (v/v) acetone solution containing $0,0.1,1$ or $2 \% \mathrm{HCl}$. The contact time was $60 \mathrm{~min}$. After the extraction, the samples were filtered through Whatman No. 1 filter paper and the residual tissues were washed with $2 \times 20 \mathrm{~mL}$ of solvent. The filtrates were combined in the total extract. Finally, the obtained peach extracts were collected in volumetric flasks $(100 \mathrm{~mL})$. The obtained extracts were used for spectrophotometric and HPLC measurements. The extractions were performed in triplicates for each peach variety.

\section{Determination of total phenolic content}

Total phenolic (TP) contents of the acetone extracts were determined using the Folin-Ciocalteau assay (Gougoulias and Mashev, 2006). $0.15 \mathrm{~mL}$ of acetone extract were mixed with 2.0 $\mathrm{mL}$ of $20 \%$ aqueous sodium carbonate solution and $0.5 \mathrm{~mL}$ of Folin-Ciocalteau's reagent and made up to $10 \mathrm{~mL}$ with deionized water. The solutions were mixed and, after ageing for
$120 \mathrm{~min}$ at $25^{\circ} \mathrm{C}$, absorbance was measured at $760 \mathrm{~nm}$, using an Agilent 8453 UV-VIS spectrophotometer (Agilent Technologies, USA). Results were expressed as mg of gallic acid equivalents (GAE) per $100 \mathrm{~g}$ of the fresh weight (f.w.).

\section{Determination of total flavonoid content}

The total flavonoid (TF) contents of peach extracts were determined by a colorimetric method according to Malencic et al. (2002). Known volumes of the samples were mixed with 2 $\mathrm{mL}$ of distilled water and subsequently with $0.3 \mathrm{~mL}$ of $5 \%$ sodium nitrite solution. After $5 \mathrm{~min}, 3 \mathrm{~mL}$ of $1 \%$ aluminum chloride solution were added and the solution left for $5 \mathrm{~min}$ at room temperature. Then, $2 \mathrm{~mL}$ of $1 \mathrm{M}$ sodium hydroxide were added to the mixtures diluted with deionized water to the final volume of $10 \mathrm{~mL}$. The mixtures were thoroughly mixed and absorbance was immediately measured at $510 \mathrm{~nm}$. Results were expressed as mg of catechin equivalent (CE) per $100 \mathrm{~g}$ of fresh weight (f.w.).

\section{Determination of antioxidant activity}

The antioxidant capacities of peach acetone extracts (peel and pulp) were studied in four antioxidant assays: scavenging DPPH radical (Brand-Williams et al., 1995), scavenging ABTS radical (Lee et al., 2003), iron (III) to iron(II) reduction power assay (RP) (Dorman et al., 2003) and ferric-reducing antioxidant power assay (FRAP) (Benzil and Strain, 1999). The total antioxidant activities of peach extracts for the first and the second assays were expressed as mmol of Trolox equivalent (TE) per 100 $\mathrm{g}$ of f.w. RPs of the extracts were expressed as mg of gallic acid equivalent (GAE) per $100 \mathrm{~g}$ of f.w., while FRAP values were expressed as mmol of ferrous ion equivalents (FE) per $100 \mathrm{~g}$ of f.w.

\section{HPLC-DAD determination of phenolics composition}

The individual phenolics were analyzed by the direct injection of the extracts (previously filtered through a $0.45 \mu \mathrm{m}$ pore size membrane filter) into Agilent 1200 chromatographic system equipped with a quaternary pump, and UV-VIS photodiode array detection (DAD) for multi wavelength detection and fluorescence detection for the acquisition of the emission response, an $8 \mu \mathrm{L}$ flow cell, and automatic injector and ChemStation software. The column temperature was $30{ }^{\circ} \mathrm{C}$. After injection of $5 \mu \mathrm{L}$ of sample extract, the separation was performed in the Agilent/eclipse XDBC-18 $4.6 \times 150 \mathrm{~mm}$ column. Two solvents were used for the gradient elution: A$\left(\mathrm{H}_{2} \mathrm{O}+5 \% \mathrm{HCOOH}\right)$ and $\mathrm{B}-(80 \% \mathrm{ACN}+5 \%$ $\left.\mathrm{HCOOH}+\mathrm{H}_{2} \mathrm{O}\right)$. The used elution program was as follows: from 0 to $10 \mathrm{~min} 0 \% \mathrm{~B}$, from 10 to $28 \mathrm{~min}$ gradually increased $0-25 \% \mathrm{~B}$, from 28 to $30 \mathrm{~min} 25 \% \mathrm{~B}$, from 30 to 35 min gradually increased $25-50 \% \mathrm{~B}$, from 35 to 40 min gradually increased 50 $80 \% \mathrm{~B}$, and finally for the last 5 min gradually decreased $80-0 \%$ B. The runs were monitored at the following wavelengths: hydroxycinnamates at $320 \mathrm{~nm}$ and flavonol glycosides at 360 nm. Retention times and spectra were compared to pure standards. Calibration curves at concentrations ranging from 0.05 to $5 \mathrm{mg} \mathrm{ml}^{-1}\left(\mathrm{r}^{2}<0.99\right)$ were made from chlorogenic acid, $p$ coumaric acid, quercetin and kaempferol-3-glucoside as standards. Neohlorogenic acid quantity was expressed as quantity of quercetin and kaempferol-3-glucoside, respectively. The results were expressed as milligrams per $\mathrm{kg}$ of fresh weight (f.w.). 


\section{Statistical analysis}

The data were reported as mean \pm standard deviation (SD) with triplicate determinations. Statistical analysis was performed using the application available for Microsoft Excel (XISTAT2016) (Addinsoft, 2016). Analysis of variance, analysis of the differences between the categories with a confidence interval of $95 \%$ (Tukey) and analysis of the differences between the control category and other categories with a confidence interval of $95 \%$ (Dunnett test) were performed.

\section{Results and Discussion}

\section{Totalphenolics}

Total phenolics of pulp and peel of the six different peach varieties ('Radmilovčanka', 'June Gold', 'Blake', 'Hale', 'Vesna' and 'Adria') and nectarine ('Fantasia') varied significantly (Table 1). The amount of total phenolics ranged from 11.1$128.5 \mathrm{mg} \mathrm{GAE} / 100 \mathrm{~g}$ f.w. for pulp extracts, and $42.7-211.4 \mathrm{mg}$ GAE/ $100 \mathrm{~g}$ f.w. for peel extracts. Among different tested peach varieties, the pulp and peel of cv. 'Radmilovčanka' exhibited the highest phenolic contents (128.5 and $211.4 \mathrm{mg} \mathrm{GAE} / 100 \mathrm{~g}$ f.w.), whereas these amounts were the lowest $(11.1$ and $47.2 \mathrm{mg}$ GAE/100 g f.w.) in cv. 'Hale'. The total phenolic contents were found to be higher than those reported in 'Radhaven' peach (5.1-10.7 mg GAE/100 g f.w. for pulps and 14.9-30.4 mg GAE/100 g f.w. for peels, respectively) (Orazem et al., 2011). However, Chang et al. (2000) showed that the total phenolic contents in pulps and peels of peach fruits were in the range 41.5-76.5 mg GAE/100 g f.w. and 87.7-189.6 mg GAE/100 g f.w. The decrease in the phenolic contents in the pulps can be attributed to chemical and enzymatic alternations of some phenolics during ripening (Remorini et al., 2008).

\section{Totalflavonoids}

Total flavonoids (TF) of pulps and peels of the six different varieties of peach and one nectarine also varied considerably (Table 1). In the peels extracts, total flavonoids ranged from $21.9-94.9 \mathrm{mg} \mathrm{CE} / 100 \mathrm{~g} \mathrm{f.w}$, whereas, these amounts decreased in the pulps extracts levels of 5.0-58.9 mg $\mathrm{CE} / 100 \mathrm{~g}$ f.w. The peel of 'Radmilovčanka' peach exhibited significantly $(p<0.05)$ higher content of flavonoids $(94.9 \mathrm{mg}$ $\mathrm{CE} / 100 \mathrm{~g}$ f.w.) compared to those of 'Adria' and 'Fantasia' (23.9 and $21.9 \mathrm{mg} \mathrm{CE} / 100 \mathrm{~g}$ f.w., respectively). In case of the pulp extract of cv. 'Radmilovčanka', higher contents of TF were observed (58.9 mg CE/100 g f.w.) whereas cv. Hale had smaller content of TF (5.0 mg CE/100 g f.w.). Also, the contents of TF determined in the peach peels were found to be higher than those of the corresponding pulps. CevallosCasals et al. (2006) also reported that contents of phenolic compounds vary within different tissues of the same fruits and are mostly concentrated in the epidermal and subepidermal layers of the fruits. Higher concentrations of TF compounds in peach peel compared to the pulp were also reported by other researchers (Tomas-Barberan et al., 2001; Scordino et al., 2012). The effect of acidified solvents on the extraction of the peach phenolics was evaluated using aqueous $\mathrm{HCl}$ in $80 \%$ acetone as the solvent. The optimal acidified conditions for the extractions of phenolic compounds were 1 $\%(\mathrm{v} / \mathrm{v}) \mathrm{HCl}$ for the pulp, and $2 \%(\mathrm{v} / \mathrm{v}) \mathrm{HCl}$ for peel.

\section{Antioxidant capacity}

There are huge varieties of antioxidants present in fruits. Therefore, measurement of the antioxidant capacity of each compound separately represents very difficult task. Several methods have been developed to determine the antioxidant potential of plant extracts. Each method provides an estimation of the capacity that depends on the time of reaction, and the complexity of the reaction kinetics. Therefore, the single antioxidant method can not give profiles of the antioxidant capacities of compounds completely. Antioxidant can reduce radicals primarily by two mechanisms: the single electron transfer and the hydrogen atom transfer. ABTS, DPPH, FRAP and RP are commonly used for the evaluation of the activity of plant extracts (Ozgen et al., 2006; Gonget al., 2012).

DPPH is a stable free radical with a deep violet colour and absorption maximum at a wavelength of $515 \mathrm{~nm}$. In this test, the violet colour of DPPH is reduced to a pale yellow colour due to the abstraction of hydrogen atom from antioxidants (Lee et al., 2003).

The DPPH radical scavenging activities of $80 \%(\mathrm{v} / \mathrm{v})$ acetone extracts using different concentrations of $\mathrm{HCl}$ of peels and pulps were tested and compared using Trolox (Table 1). Peel extracts from all peach cultivars exhibited appreciably higher scavenging activities, ranging from $0.2-0.4 \mathrm{mmol} \mathrm{TE} / 100 \mathrm{~g}$ f.w. compared to pulp extracts $(0.1-0.3 \mathrm{mmol} \mathrm{TE} / 100 \mathrm{~g}$ f.w $)$. The peel extract from 'Radmilovčanka' exhibited the highest scavenging activity. In case of pulp extracts, the highest scavenging capacities were recorded for 'Radmilovčanka'. Analyses of variances (ANOVA) revealed significant variations $(\mathrm{p}<0.05)$ in radical scavenging capacities between peels and pulps. Cantin et al. (2009) and Reig et al. (2013) reported similar results $0.1-0.2,0.1-0.2 \mathrm{mmol}$ TE/100 $\mathrm{g}$ f.w., respectively.

FRAP assay is commonly used to study the antioxidant capacity of plant materials. The antioxidant capacity of fruits extracts is determined by the ability of the antioxidants to reduce ferric iron to ferrous in FRAP reagent, which consists of 2,4,6tris(1-pyridyl)-5-triazine (TPTZ) prepared in sodium acetate buffer, $\mathrm{pH}$ 3.6. The reduction of ferric iron in FRAP reagent results in the formation of a blue product (ferrous-TPTZ complex) which absorbance can be read at $593 \mathrm{~nm}$. The antioxidant capacity of peel $(0.41 \mathrm{mmol} \mathrm{Fe} / 100 \mathrm{~g}$ f.w. $)$ was higher than in pulp (0.3-0.7 mmol Fe/100 g f.w.). Similar results were reported by Guo et al. (2003) ( 0.4 for pulp and $0.9 \mathrm{mmol} \mathrm{Fe} / 100 \mathrm{~g}$ f.w. for peel, respectively), (Stratil et al., 2006; Remorini et al., 2008). In general, cultivars with higher total phenolic content showed high antioxidant capacity (Table 1). We found that the highest antioxidant capacities were present in 'Radmilovčanka' and 'June Gold'.

The assessment of reducing power (RP) of a compound may act as a good indicator of its potential antioxidant activity. The presence of the reducing agents in a typical sample causes the reduction of $\mathrm{Fe}^{3+}$ to $\mathrm{Fe}^{2+}$, and reductive capability can be monitored colorimetrically due to the formation of Perl's Prussian blue complex at $700 \mathrm{~nm}$ (Dorman et al., 2003; Lim and Quah, 2007). Table 1 gives the reductive capability of peel and pulp extracts of different cultivars of peach fruit. The reducing potentials of the tested extracts were recorded over a range of 3.8 to $70.5 \mathrm{mg}$ GAE/100 g f.w. Generally, the extracts from peels showed significantly higher reductive capabilities than the pulp extracts.

$\mathrm{ABTS}^{\circ+}$, a protonated radical, has a characteristic absorbance at $734 \mathrm{~nm}$ that decreases with the scavenging of proton radicals 
178

(Mohdaly et al., 2010). The extracts demonstrated a wide range of $\mathrm{ABTS}^{\circ+}$ scavenging activities from 0.2 to $0.7 \mathrm{mmol} \mathrm{TE} / 100 \mathrm{~g}$ f.w. (Table 1).

Scavenging of the $\mathrm{ABTS}^{\circ+}$ radicals by extracting was found to be higher than DPPH radical. Factors such as the stereoselectivity of radicals and the solubility of extracts in different test systems have been reported to affect the capacity of extracts to react with and quench different radicals (Yu et al., 2012). Similar results were found by Montevecchi et al. (2012) for Sicilian white peach cultivar $(0.7-2.3 \mathrm{mmol} \mathrm{TE} / 100 \mathrm{~g}$ f.w. for pulp and $0.4-1.4 \mathrm{mmol}$ $\mathrm{TE} / 100 \mathrm{~g}$ f.w. for peel).

In our study, all extracts exhibited significant antioxidant activities. Extracts with $1 \%$ for pulp and $2 \%(\mathrm{v} / \mathrm{v}) \mathrm{HCl}$ for peel, respectively, contain the most efficient $\mathrm{ABTS}^{+1}$ scavengers. Acidity of solvent alters its ability to dissolve selected groups of antioxidant compounds.

From ANOVA analysis it was determined that 'Radmilovčanka' and TP are highly positively correlated (0.783), while medium positive correlation was noticed in case of 'June Gold' (0.291) and 'Peel' (0.336). Medium negative correlation was observed in case of 'Blake' (-0.219), 'Hale' (-0.311), 'Adria' ($0.204)$, 'Fantasia' (-0.291) and 'Pulp' (-0.336). Regarding 'TF', the situation is similar: high positive correlation in case of 'Radmilovčanka' (0.738), medium positive correlation with 'June Gold' (0.306) and 'Peel' (0.396), and medium negative correlation in case of 'Blake' (-0.198), 'Hale' (-0.318), 'Adria' (-0.210), 'Fantasia' (-0.291) and 'Pulp' (-0.396). DPPH is in high positive correlation with 'Radmilovčanka' (0.665) and 'Peel' (0.514), and in negative correlation with 'Blake' $(-0.315)$, 'Hale' $(-0.315)$, 'Fantasia' $(-0.315)$ and 'Pulp' (-0.514). In case of ABTS, the situation is as follows: high positive correlation with 'Radmilovčanka' (0.635), 'June Gold' (0.348), and 'Peel' (0.351), and negative correlation with 'Blake' (-0.225), 'Hale' (-0.369), 'Adria' (-0.225), 'Fantasia' ($0.369)$ and 'Pulp' (-0.351). FRAP shows the following correlations: strong positive correlation with 'Radmilovčanka' (0.702) and 'Peel' (0.459), medium positive correlation with 'June Gold' (0.265), and medium negative correlation with 'Hale' ($0.281)$, 'Fantasia' (-0.390) and 'Pulp' (-0.459). RP similarly gives: high positive correlation with 'Radmilovčanka' (0.799), medium positive correlation with 'June Gold' (0.273) and 'Peel' (0.333), and medium negative correlation with 'Blake' (-0.207), 'Hale' ($0.309)$, 'Adria' (-0.204), 'Fantasia' (-0.281) and 'Pulp' (-0.333). Obtained $\mathrm{R}^{2}$ values were 0.945 (TP), 0.936 (TF), $0.956(\mathrm{DPPH})$, 0.929 (ABTS), 0.944 (FRAP) and 0.948 (RP); they show that few other factors beside peach and nectarine cultivar and part of the fruit (pulp and peel) must be taken into account for the explanation of variance. The values of " $\mathrm{p}$ " were 0.002 (TP), 0.003 (TF), 0.001 (DPPH), 0.004 (ABTS), 0.002 (FRAP) and 0.002 (RP), and all of them are less than 0.05 , so all models are valid. In all cases there are no outliers because all values are within the limit $[-2$, 2] which corresponds to the Normal distribution. Tukey test with a confidence interval of $95 \%$ shows that in case of: TP, 'Radmilovčanka' is different from 'Blake' (0.005), 'Hale' (0.003), 'Vesna' (0.012), 'Adria' (0.005), and 'Fantasia' (0.003); TF, 'Radmilovčanka' is different from 'Blake' (0.010), 'Hale' (0.005), 'Vesna' (0.025), 'Adria' (0.009), and 'Fantasia' (0.006); DPPH, 'Radmilovčanka' is different from 'Blake' (0.003), 'Hale' (0.003), 'Adria' (0.013), and 'Fantasia' (0.003); ABTS, 'Radmilovčanka' is different from 'Blake' (0.018), 'Hale' (0.009), 'Adria' (0.018), and 'Fantasia' (0.009), and moreover 'June Gold' from 'Hale' (0.042) and 'Fantasia' (0.042); FRAP, 'Radmilovčanka' is different from 'Blake' (0.009), 'Hale' (0.005), 'Adria' (0.009), and 'Fantasia' $(0.003)$, and moreover 'June Gold' from 'Fantasia' (0.037); and $\mathrm{RP}$, 'Radmilovčanka' is different from 'Blake' (0.004), 'Hale' (0.002), 'Vesna' (0.008), 'Adria' (0.004), and 'Fantasia' (0.003). Dunnett test gives that 'Radmilovčanka' is different from all other peach and nectarine cultivar except 'June Gold' in all cases except DPPH (difference with all, including 'June Gold'), ABTS (difference with all except 'June Gold' and 'Vesna') and RP (difference with all, including 'June Gold').

In general, most phenolics and flavonoids exhibit some degrees of antioxidant activities. Therefore, the extracts with higher contents of phenolics and flavonoids would generally show stronger antioxidant activities. The correlations between antioxidant activities and the contents of phenolics and flavonoids have also been reported by other researchers (Ozgen et al., 2006; Vizzoto et al., 2007). In the present study, the acetone extract $(80 \%, 2 \% \mathrm{HCl})$ exhibited the highest antioxidant activity in the mentioned four assays, and the extract with acetone $(80 \%, 0 \%$ $\mathrm{HCl}$ ) showed the lowest activity.

Table 1. Total phenolics contents, total flavonoid contents and antioxidant activities of peel and pulp extracts obtained with two solvent mixtures (mean of three replicates \pm standard deviation ${ }^{*}$ )

\begin{tabular}{|c|c|c|c|c|c|c|c|}
\hline $\begin{array}{l}\text { Peach and } \\
\text { nectarine cultivar }\end{array}$ & Part & $\begin{array}{l}\text { TP as GAE } \\
(\mathrm{mg} / 100 \mathrm{~g})\end{array}$ & $\begin{array}{l}\text { TF as CE } \\
(\mathrm{mg} / 100 \mathrm{~g})\end{array}$ & $\begin{array}{l}\text { DPPH as TE } \\
(\mathrm{mmol} / 100 \mathrm{~g})\end{array}$ & $\begin{array}{l}\text { ABTS as TE } \\
(\mathrm{mmol} / 100 \mathrm{~g})\end{array}$ & $\begin{array}{l}\text { FRAP as FeE } \\
(\mathrm{mmol} / 100 \mathrm{~g})\end{array}$ & $\begin{array}{l}\mathrm{RP} \text { as } \mathrm{GAE} \\
(\mathrm{mg} / 100 \mathrm{~g})\end{array}$ \\
\hline \multirow{2}{*}{ Radmilovčanka } & Peel $^{a}$ & $211.4 \pm 1.0$ & $94.9 \pm 1.0$ & $0.4 \pm 0.0$ & $0.7 \pm 0.0$ & $1.0 \pm 0.0$ & $70.5 \pm 0.4$ \\
\hline & Pulp $^{\mathrm{b}}$ & $128.5 \pm 1.3$ & $58.9 \pm 1.0$ & $0.3 \pm 0.0$ & $0.5 \pm 0.0$ & $0.7 \pm 0.0$ & $42.8 \pm 0.7$ \\
\hline \multirow{2}{*}{ June Gold } & Peel $^{a}$ & $131.7 \pm 1.2$ & $68.1 \pm 0.7$ & $0.3 \pm 0.0$ & $0.5 \pm 0.0$ & $0.7 \pm 0.0$ & $42.5 \pm 0.6$ \\
\hline & Pulp ${ }^{b}$ & $81.4 \pm 1.0$ & $35.6 \pm 0.3$ & $0.2 \pm 0.0$ & $0.5 \pm 0.0$ & $0.6 \pm 0.0$ & $25.4 \pm 0.3$ \\
\hline \multirow{2}{*}{ Blake } & Peel $^{\mathrm{a}}$ & $60.7 \pm 0.7$ & $34.2 \pm 0.4$ & $0.2 \pm 0.0$ & $0.4 \pm 0.0$ & $0.6 \pm 0.0$ & $19.6 \pm 0.1$ \\
\hline & Pulp ${ }^{b}$ & $21.3 \pm 0.2$ & $11.1 \pm 0.3$ & $0.1 \pm 0.0$ & $0.2 \pm 0.0$ & $0.3 \pm 0.0$ & $6.9 \pm 0.1$ \\
\hline \multirow{2}{*}{ Hale } & Peel $^{a}$ & $47.2 \pm 0.3$ & $26.3 \pm 0.4$ & $0.2 \pm 0.0$ & $0.3 \pm 0.0$ & $0.5 \pm 0.0$ & $13.9 \pm 0.1$ \\
\hline & Pulp ${ }^{b}$ & $11.1 \pm 0.3$ & $5.0 \pm 0.2$ & $0.1 \pm 0.0$ & $0.2 \pm 0.0$ & $0.3 \pm 0.0$ & $3.8 \pm 0.0$ \\
\hline \multirow{2}{*}{ Vesna } & Peel $^{a}$ & $69.7 \pm 0.7$ & $35.0 \pm 0.3$ & $0.3 \pm 0.0$ & $0.5 \pm 0.0$ & $0.6 \pm 0.0$ & $21.8 \pm 0.3$ \\
\hline & Pulp & $55.9 \pm 0.6$ & $29.9 \pm 0.6$ & $0.2 \pm 0.0$ & $0.4 \pm 0.0$ & $0.5 \pm 0.0$ & $16.4 \pm 0.2$ \\
\hline \multirow{2}{*}{ Adria } & Peel $^{\mathrm{a}}$ & $44.2 \pm 0.8$ & $23.9 \pm 0.2$ & $0.2 \pm 0.0$ & $0.3 \pm 0.0$ & $0.5 \pm 0.0$ & $14.2 \pm 0.2$ \\
\hline & Pulp ${ }^{b}$ & $41.7 \pm 0.8$ & $20.0 \pm 0.1$ & $0.2 \pm 0.0$ & $0.3 \pm 0.0$ & $0.4 \pm 0.0$ & $12.6 \pm 0.1$ \\
\hline \multirow{2}{*}{ Fantasia } & Peel $^{a}$ & $42.7 \pm 0.5$ & $21.9 \pm 0.2$ & $0.2 \pm 0.0$ & $0.3 \pm 0.0$ & $0.4 \pm 0.0$ & $13.8 \pm 0.1$ \\
\hline & Pulp $^{\mathrm{b}}$ & $20.9 \pm 0.6$ & $12.6 \pm 0.1$ & $0.1 \pm 0.0$ & $0.2 \pm 0.0$ & $0.3 \pm 0.0$ & $6.3 \pm 0.1$ \\
\hline
\end{tabular}

${ }^{*}$ Values are expressed as means $\pm \mathrm{SD}(\mathrm{n}=5),{ }^{\mathrm{a}}$ in acetone extracts with $2 \% \mathrm{HCl} ;{ }^{\mathrm{b}}$ in acetone extracts with $1 \% \mathrm{HCl}$. 
Individual phenolics in peels and pulps of peach varieties

The extracts of peels and pulps from six different peach cultivars and one nectarine were analyzed by HPLC-DAD. The compounds were identified by comparison with those of standards at $200-400 \mathrm{~nm}$. The HPLC chromatograms of three acids, i.e. neochlorogenic acid (peak 1), chlorogenic acid (peak 2) and $p$ coumaric acid (peak 3) found in peel peach extract recorded at 320 $\mathrm{nm}$ with a diode detector, are shown in Fig. 1. In Table 2, we show phenolic compounds (neochlorogenic acid, chlorogenic acid, and p-coumaric acid) in pulp and peel, and in Table 3 flavonols (quercetin-3-rutinoside, quercetin-3-glucoside, quercetin-3rhamnoside and kaempferol-3-rutinoside) in the peel of peach fruit.

From ANOVA analysis it was determined that 'Radmilovčanka' and neochlorogenic acid are highly positively correlated (0.479) and 'Vesna' as well (0.522), while medium positive correlation was noticed in case of Peel $(0.288)$. Medium negative correlation was observed in case of 'Hale' $(-0.333)$, 'Adria' (-0.265), 'Fantasia' (-0.324) and 'Pulp' (-0.288). Regarding chlorogenic acid, the situation is similar: high positive correlation in case of 'Radmilovčanka' (0.539) and 'Peel' (0.484), medium positive correlation with 'Vesna' (0.302), and medium negative correlation in case of 'Hale' (-0.257), 'Adria' (-0.244), 'Fantasia' (0.277 ) and 'Pulp' (-0.484). $p$-Coumaric acid is in high positive correlation with 'Radmilovčanka' (0.649) and 'Peel' (0.452), and in high negative correlation with 'Adria' (-0.324), 'Fantasia' (-0.354) and 'Pulp' (-0.452). In case of total acids, the situation is as follows: high positive correlation with 'Radmilovčanka' (0.536), 'Vesna' (0.351), and 'Peel' (0.449), and negative correlation with 'Hale'($0.278)$, 'Adria' (-0.252), 'Fantasia' (-0.292) and Pulp (-0.449). Obtained $\mathrm{R}^{2}$ values were 0.833 (Neochlorogenic acid), 0.779 (Chlorogenic acid), 0.828 (p-Coumaric acid), and 0.798 (Total acids); they show that few other factors beside peach and nectarine cultivar, concentration of $\mathrm{HCl}$ and part of the fruit (pulp and peel) must be taken into account for the explanation of the variance. The values of $\mathrm{p}$ were $<0.0001$ (Neochlorogenic acid), $<0.0001$ (Chlorogenic acid), $<0.0001$ ( $p$-Coumaric acid), and $<0.0001$ (Total acids); all of them are less than 0.05 , so all models are valid. Only two residuals were outside the limit $[-2,2]$ (outliers). Tukey test with a confidence interval of $95 \%$ shows that in case of:

Table 2. Individual hydroxycinnamic acids contents $(\mathrm{mg} / \mathrm{kg})$ in peels and pulps of six different peach and one nectarine cultivars

\begin{tabular}{|c|c|c|c|c|c|c|c|c|c|}
\hline \multirow{3}{*}{$\begin{array}{l}\text { Peach and } \\
\text { nectarine cultivars }\end{array}$} & \multirow{3}{*}{$\begin{array}{c}\mathrm{HCl} \\
(\%)\end{array}$} & \multicolumn{8}{|c|}{$\omega /\left(\mathrm{mg} \mathrm{kg}^{-1}\right)$} \\
\hline & & \multicolumn{4}{|c|}{ Peel } & \multicolumn{4}{|c|}{ Pulp } \\
\hline & & Neochlor. & Chlor. & p-Coum. & $\sum$ acid & Neochlor. & Chlor. & p-Coum. & $\sum$ acid \\
\hline \multirow{4}{*}{ Radmilovčanka } & 0 & 63.0 & 242.3 & 3.8 & 309.2 & 29.5 & 81.7 & 2.4 & 113.6 \\
\hline & 0.1 & 83.1 & 273.9 & 4.6 & 361.6 & 30.1 & 81.2 & 2.5 & 113.8 \\
\hline & 1 & 84.5 & 299.6 & 5.1 & 389.2 & 34.8 & 89.2 & 3.3 & 127.3 \\
\hline & 2 & 74.9 & 279.5 & 4.4 & 358.9 & 26.6 & 64.2 & 2.0 & 92.8 \\
\hline \multirow{4}{*}{ June Gold } & 0 & 21.8 & 76.1 & 2.1 & 100.0 & 25.9 & 16.0 & 0.7 & 42.6 \\
\hline & 0.1 & 32.7 & 123.3 & 2.9 & 161 & 22.4 & 18.4 & 0.7 & 41.4 \\
\hline & 1 & 75.2 & 280.4 & 4.4 & 360.1 & 27.0 & 24.4 & 1.0 & 52.4 \\
\hline & 2 & 25.8 & 80.4 & 2.4 & 108.6 & 25.9 & 22.5 & 0.8 & 49.2 \\
\hline \multirow{4}{*}{ Blake } & 0 & 22.5 & 50.4 & 2.5 & 75.4 & 11.3 & 11.6 & 0.5 & 23.4 \\
\hline & 0.1 & 15.1 & 55.3 & 2.9 & 73.3 & 13.6 & 13.2 & 0.5 & 27.3 \\
\hline & 1 & 27.0 & 115.3 & 3.4 & 145.7 & 19.2 & 23.5 & 0.5 & 43.2 \\
\hline & 2 & 15.6 & 107.8 & 2.0 & 125.4 & 17.6 & 20.3 & 0.4 & 38.4 \\
\hline \multirow{4}{*}{ Hale } & 0 & 13.7 & 29.9 & 1.2 & 44.8 & 2.6 & 6.3 & / & 8.9 \\
\hline & 0.1 & 14.5 & 32.5 & 1.1 & 48.1 & 3.1 & 8.5 & / & 11.6 \\
\hline & 1 & 16.1 & 39.8 & 1.7 & 57.6 & 4.8 & 9.1 & / & 13.9 \\
\hline & 2 & 13.8 & 35.2 & 1.5 & 50.5 & 2.1 & 6.4 & / & 8.5 \\
\hline \multirow{4}{*}{ Vesna } & 0 & 57.8 & 126.1 & 1.2 & 185.2 & 45.3 & 80.0 & 1.2 & 126.5 \\
\hline & 0.1 & 57.4 & 184.7 & 1.4 & 243.4 & 44.8 & 77.7 & 1.1 & 123.7 \\
\hline & 1 & 73.0 & 226.3 & 2.3 & 301.7 & 65.1 & 99.7 & 1.0 & 165.8 \\
\hline & 2 & 50.9 & 169.1 & 2.0 & 222.0 & 51.0 & 77.4 & 2.2 & 130.6 \\
\hline \multirow{4}{*}{ Adria } & 0 & 7.5 & 20.2 & 0.7 & 28.4 & 9.1 & 12.2 & 0.3 & 21.7 \\
\hline & 0.1 & 9.1 & 23.2 & 0.9 & 33.2 & 10.9 & 12.3 & 0.4 & 23.6 \\
\hline & 1 & 23.1 & 58.3 & 1.0 & 82.3 & 15.7 & 17.5 & 0.6 & 33.8 \\
\hline & 2 & 10.1 & 28.8 & 0.7 & 39.6 & 15.0 & 16.6 & 0.6 & 32.3 \\
\hline \multirow{4}{*}{ Fantasia } & 0 & 8.9 & 31.3 & 0.9 & 41.1 & 5.6 & 5.0 & 0.2 & 10.9 \\
\hline & 0.1 & 10.5 & 23.2 & 0.8 & 34.5 & 5.7 & 5.4 & 0.2 & 11.4 \\
\hline & 1 & 16.9 & 33.0 & 1.0 & 50.9 & 7.3 & 7.4 & 0.4 & 15.2 \\
\hline & 2 & 13.8 & 27.4 & 0.7 & 41.9 & 5.8 & 4.5 & 0.3 & 10.6 \\
\hline
\end{tabular}


180

Table 3. Individual flavanol acid contents $(\mathrm{mg} / \mathrm{kg})$ in peels of six different peach and one nectarine cultivars

\begin{tabular}{|c|c|c|c|c|c|c|}
\hline \multirow{2}{*}{$\begin{array}{l}\text { Peach and } \\
\text { nectarine } \\
\text { cultivars }\end{array}$} & \multirow{2}{*}{$\begin{array}{c}\mathrm{HCl} \\
(\%)\end{array}$} & \multicolumn{5}{|c|}{$\omega /\left(\mathrm{mg} \mathrm{kg}^{-1}\right)$} \\
\hline & & Q-rut. & Q-glu. & $\begin{array}{c}\text { Q- } \\
\text { rham. }\end{array}$ & $\begin{array}{c}\text { Kae- } \\
\text { rut. }\end{array}$ & $\sum$ flav. \\
\hline \multirow{4}{*}{ Radmilovčanka } & 0 & 13.8 & 8.5 & 2.5 & 7.0 & 31.8 \\
\hline & 0.1 & 18.0 & 10.4 & 3.0 & 8.9 & 40.3 \\
\hline & 1 & 18.6 & 11.2 & 3.0 & 11.4 & 44.2 \\
\hline & 2 & 20.3 & 13.4 & 5.2 & 15.0 & 54.0 \\
\hline \multirow{4}{*}{ June Gold } & 0 & 14.1 & 8.7 & 3.0 & 8.6 & 34.3 \\
\hline & 0.1 & 17.3 & 10.5 & 3.3 & 8.1 & 35.8 \\
\hline & 1 & 7.7 & 4.3 & 3.4 & 6.9 & 22.3 \\
\hline & 2 & 17.7 & 12.1 & 3.4 & 9.4 & 42.6 \\
\hline \multirow{4}{*}{ Blake } & 0 & 9.8 & 7.4 & 2.0 & 4.8 & 24.1 \\
\hline & 0.1 & 10.8 & 6.8 & 2.0 & 4.7 & 24.4 \\
\hline & 1 & 10.9 & 5.5 & 1.8 & 5.1 & 23.3 \\
\hline & 2 & 12.5 & 9.1 & 2.5 & 6.7 & 30.8 \\
\hline \multirow{4}{*}{ Hale } & 0 & 10.0 & 4.3 & 2.3 & 7.2 & 24.0 \\
\hline & 0.1 & 10.3 & 5.2 & 2.8 & 7.0 & 25.4 \\
\hline & 1 & 11.2 & 5.4 & 2.9 & 5.1 & 24.6 \\
\hline & 2 & 11.7 & 5.7 & 3.9 & 8.1 & 29.4 \\
\hline \multirow{4}{*}{ Vesna } & 0 & 6.6 & 3.9 & 4.6 & 4.2 & 19.4 \\
\hline & 0.1 & 6.2 & 3.8 & 4.8 & 4.3 & 19.0 \\
\hline & 1 & 11.2 & 4.2 & 5.1 & 5.3 & 25.7 \\
\hline & 2 & 13.3 & 6.7 & 5.7 & 5.9 & 31.6 \\
\hline \multirow{4}{*}{ Adria } & 0 & 10.6 & 4.3 & 1.7 & 7.5 & 24.1 \\
\hline & 0.1 & 11.2 & 4.0 & 1.4 & 9.6 & 26.3 \\
\hline & 1 & 11.9 & 4.7 & 1.7 & 8.5 & 26.8 \\
\hline & 2 & 12.5 & 7.9 & 1.9 & 9.9 & 32.2 \\
\hline \multirow{4}{*}{ Fantasia } & 0 & 9.6 & 6.3 & 1.6 & 5.1 & 22.7 \\
\hline & 0.1 & 7.8 & 5.3 & 1.3 & 2.8 & 17.3 \\
\hline & 1 & 8.4 & 6.5 & 1.5 & 3.6 & 20.1 \\
\hline & 2 & 10.0 & 7.3 & 1.7 & 5.9 & 25.0 \\
\hline
\end{tabular}

Neochlorogenic acid, 'Radmilovčanka' is different from 'June Gold' (0.003), 'Blake' (<0.0001), 'Hale' $(<0.0001)$, 'Adria' $(<0.0001)$, and 'Fantasia' $(<0.0001)$, moreover, 'June Gold' is different from 'Hale' (0.001), 'Vesna' (0.001), 'Adria' (0.007) and 'Fantasia' (0.001), and 'Vesna' from 'Hale' $(<0.0001)$, 'Fantasia' $(<0.0001)$, 'Adria' $(<0.0001)$ and 'Blake' $(<0.0001)$; Chlorogenic acid, 'Radmilovčanka' is different from 'June Gold' (0.001), 'Blake' $(<0.0001)$, 'Hale' $(<0.0001)$, 'Adria' $(<0.0001)$, and 'Fantasia' $(<0.0001)$, moreover, 'Vesna' is different from 'Fantasia' $(<0.0001)$,'Hale' (<0.0001), 'Adria' (0.000) and 'Blake' (0.006); pCoumaric acid, 'Radmilovčanka' is different from 'June Gold' $(<0.0001)$, 'Blake' $(<0.0001),{ }^{\prime} \mathrm{Hale}^{\prime}(<0.0001),{ }^{\prime}$ Vesna' $(<0.0001)$, 'Adria' $(<0.0001)$, and 'Fantasia' $(<0.0001)$, and moreover 'June Gold' is different from 'Adria' (0.003) and 'Fantasia' (0.001), and 'Blake' from 'Adria' (0.039) and 'Fantasia' (0.018), and 'Vesna' from 'Fantasia' (0.025); and Total acids, 'Radmilovčanka' is different from 'June Gold' (0.001), 'Blake' $(<0.0001)$, 'Hale' $(<0.0001)$, 'Adria' $(<0.0001)$, and 'Fantasia' $(<0.0001)$, and moreover 'June Gold' from 'Hale' (0.030) and 'Fantasia' (0.021), and 'Vesna' from 'Blake' (0.001), 'Hale' $(<0.0001)$, 'Adria' $(<0.0001)$ and 'Fantasia' $(<0.0001)$. Dunnett test gives that 'Radmilovčanka' is different from all other peach and nectarine cultivar except 'Vesna' in all cases except $p$-Coumaric acid (difference with all, including 'Vesna').

From ANOVA analysis it was determined that 'Radmilovčanka' and Q-rut. are highly positively correlated (0.655), while medium positive correlation was noticed in case of 'June Gold' (0.259) and $\mathrm{HCl} 2 \%(0.334)$. Medium negative correlation was observed in case of 'Vesna' (-0.297), 'Fantasia'

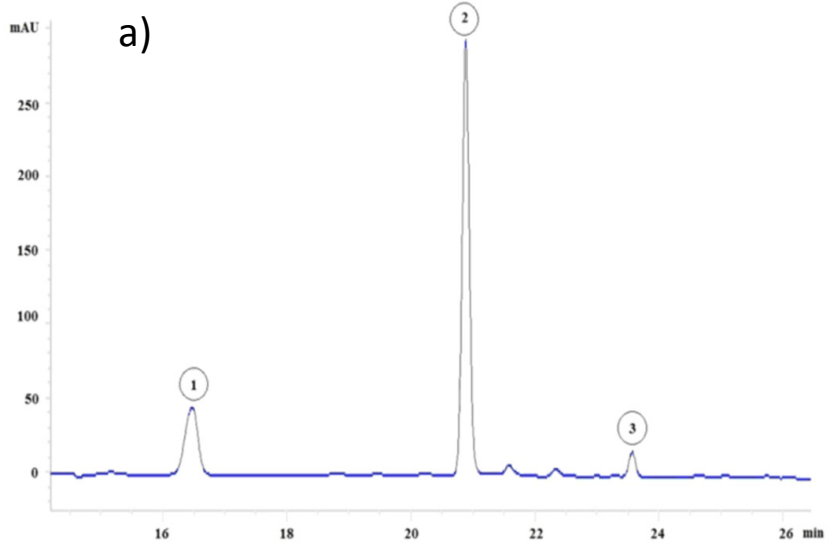

b)

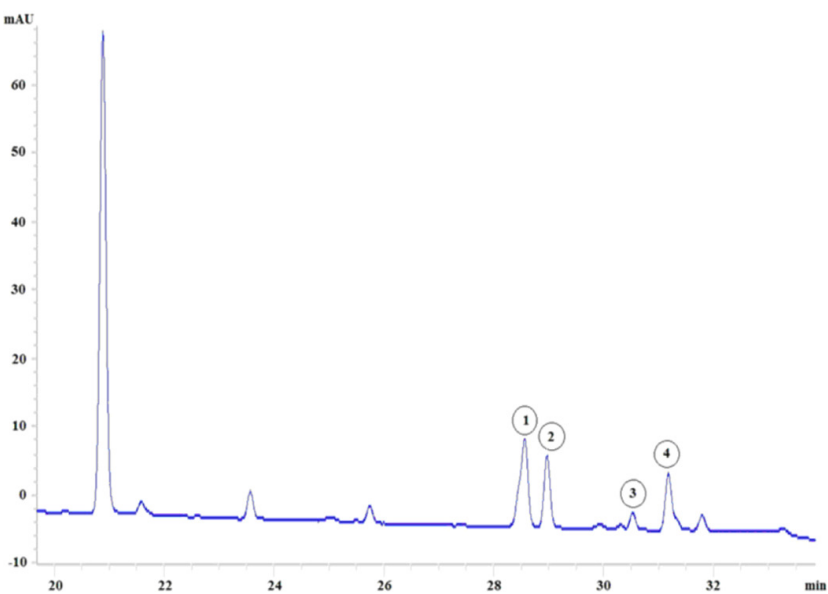

Fig. 1. The HPLC chromatogram in peel peach extracts: a) neochlorogenic acid (peak 1), chlorogenic acid (peak 2) and $p$ coumaric acid (peak 3) recorded at $320 \mathrm{~nm}$ and b) quercetin-3rutinoside (peak 1), quercetin-3-glucoside (peak 2), quercetin3-rhamnoside (peak 3), kaempferol-3-rutinoside (peak 4) recorded at $360 \mathrm{~nm}$.

$(-0.340)$ and $\mathrm{HCl} 0 \%(-0.207)$. Regarding Q-glu., the situation is similar: high positive correlation in case of 'Radmilovčanka' (0.612), medium positive correlation with 'June Gold' (0.307), $\mathrm{HCl} 2 \%(0.432)$, and medium negative correlation in case of 'Hale' (-0.271), 'Vesna' (-0.348), 'Adria'(-0.259) and $\mathrm{HCl} 1 \%$ $(-0.204)$. Q-rham. is in high positive correlation with 'Vesna' (0.719), medium positive correlation with $\mathrm{HCl} 2 \%(0.285)$, and in medium negative correlation with 'Blake' (-0.256), 'Adria' (-0.388) and 'Fantasia' (-0.437). In case of Kae-rut., the situation is as follows: high positive correlation with 'Radmilovčanka' $(0.563)$, medium with 'Adria' (0.294), and $\mathrm{HCl} 2 \%(0.376)$, and negative correlation with 'Blake' (-0.269), 'Vesna' (-0.332), and 'Fantasia' ($0.423)$. Flav. is in high positive correlation with 'Radmilovčanka' (0.681), medium positive correlation with 'June Gold' ( 0.250$)$ and $\mathrm{HCl} 2 \%(0.446)$, and medium negative correlation with 'Vesna' (0.229 ) and 'Fantasia' (-0.359). Obtained $R^{2}$ values were $0.748(\mathrm{Q}$ rut.), 0.828 (Q-glu.), 0.925 (Q-rham.), 0.830 (Kae-rut.) and 0.845 (flav.); they show that few other factors beside peach and nectarine cultivar, and concentration of $\mathrm{HCl}$ must be taken into account for the explanation of variance. The values of $\mathrm{p}$ were 0.001 (Q-rut.), $<0.0001$ (Q-glu.), $<0.0001$ (Q-rham.), $<0.0001$ (Kae-rut.) and $<0.0001$ (llav.); all of them are less than 0.05 , so all models are valid. 
Only one residual was outside the limit $[-2,2]$ (outlier) which corresponds to the Normal distribution in case of Q-rut., one in case of Q-glu., one in Q-rham., two in Kae-rut. and one in case of flav. Tukey test with a confidence interval of $95 \%$ shows that in case of: Q-rut., 'Radmilovčanka' is different from 'Blake' (0.008), 'Hale' (0.006), 'Vesna' (0.001), 'Adria' (0.016), and 'Fantasia' (0.001), moreover, 'June Gold' is different from 'Fantasia' (0.049); Q-glu., 'Radmilovčanka' is different from 'Blake' (0.019), 'Hale' (0.000), 'Vesna' (<0.0001), 'Adria' (0.000), and 'Fantasia' (0.003), moreover, 'June Gold' is different from 'Hale' (0.016), 'Vesna' $(0.005)$ and 'Adria' (0.019); Q-rham., 'Radmilovčanka' is different from 'Blake' (0.004), 'Vesna' (0.001), 'Adria' (0.000), and 'Fantasia' $(0.000)$, and moreover 'June Gold' is different from 'Blake' (0.013), 'Vesna' (0.000), 'Adria' (0.001) and 'Fantasia' (0.000), and 'Hale' from 'Adria' (0.006), 'Vesna' (<0.0001) and 'Fantasia' (0.002), and 'Vesna' from 'Blake' $(<0.0001)$, 'Adria' $(<0.0001)$ and 'Fantasia' $(<0.0001)$; Kae-rut., 'Radmilovčanka' is different from 'Blake' (0.000), 'Hale' (0.013), 'Vesna' (0.000) and 'Fantasia' $(<0.0001)$, and moreover 'June Gold' from 'Vesna' (0.031) and 'Fantasia' (0.002); and flav., 'Radmilovčanka' is different from 'Blake' (0.000), 'Hale' (0.000), 'Vesna' (<0.0001), 'Adria' (0.001) and 'Fantasia' (<0.0001), and moreover 'June Gold' is different from 'Vesna' (0.042) and 'Fantasia' (0.006). Dunnett test gives that 'Radmilovčanka' is different from all other peach and nectarine cultivars except 'June Gold' in all cases except Q-rham. (difference with 'Hale' as well), Kae-rut. (difference with 'Adria' as well) and flav. (no differences).

HPLC analysis showed that hydroxycinnamates and flavonols were abundant compounds in peach peel extracts (Table 2). Hydroxycinnamates were represented primarily as neohlorogenic acid, which ranged from 2.1 to $65.1 \mathrm{mg} \mathrm{kg}^{-1}$ f.w. for pulp extracts and 7.5 to $84.5 \mathrm{mg} \mathrm{kg}^{-1}$ f.w. for peel extracts, and chlorogenic acid, ranging from 4.5 to $99.7 \mathrm{mg} \mathrm{kg}^{-1}$ f.w. for pulp extracts and 20.2 to $299.6 \mathrm{mg} \mathrm{kg}^{-1}$ f.w. for peel extracts. Obtained contents are similar to those from the previous studies (Tomas-Barberan et al., 2001; Cantin et al., 2009). However, they are higher compared to those reported by Orazem et al. (2011). Differences occurred due to different extraction and analysis methods. Chlorogenic acid was present as the major compound in each cultivar. This result is in agreement with previous reports (Tomas-Barberan et al., 2001; Cantin et al., 2009). Profoundly higher levels of chlorogenic acid were found in the peel extracts. 'Radmilovčanka' peel extracts contained the highest amount of chlorogenic acid among all peach extracts. Phenolic acids are maturity dependent (Concalves et al., 2004). Due to the fact that fruits from each cultivar were of similar ripeness and the same geographical region, observed differences can only be attributed to the cultivar, which is in accordance with the previous studies on peach (Orazem et al, 2011).

Our analysis revealed a flavonol contents similar to those reported by Orazem et al. (2011) in 'Redhaven' peach fruit (Table 3). They found quercetin-3-glucoside and quercetin-3-rhamnoside in the peel of peach fruit. In our results, 'Radmilovčanka' contained the highest content of flavonol determined among investigated peach cultivars followed by 'June Gold', 'Adria', 'Vesna', 'Blake', 'Hale' and 'Fantasia'. Scordino et al. (2012) determined six peach flavonols: quercetin-3-rutinoside, quercetin-3-galactoside, quercetin-3-glucoside, kaempferol-3-rutinoside, isorhamnetin-3rutinoside and isorhamnetin-3-glucoside. They speculated that kaempferol and isorhamnetin flavonols in peach may be characteristics of Sicilian cultivars. The results of this study confirmed the presence of kaempferol-3-rutinoside in all peel samples. The contents of kaempferol-3-rutinoside were in the range of 2.8 to $15.0 \mathrm{mg} \mathrm{kg}^{-1}$ f.w. Scordino et al. (2012) gave similar values (3.7-12 $\mathrm{mgkg}^{-1}$ f.w.).

Previous studies have only shown quercetin derivatives (Tomas-Barberan et al., 2001; Cantin et al., 2009; Orazem et al., 2011). Present analysis of peach revealed the presence of quercetin derivatives and kaempferol-rutinoside. Scordino et al. (2012) have shown the occurrence of quercetin kaempferol and isorhamnetin flavonols in peach. Sicilian peaches contain kaempferol-3rutinoside in the range $6.8-10.6 \mathrm{mg} \mathrm{kg}^{-1}$ f.w. The HPLC chromatogram of flavonols is shown in Fig. 1 .

\section{Conclusion}

In both peel and pulp, the predominant group of polyphenolics was hydroxycinnamates. Hydroxycinnamic acids represent $18.41 \%$ of the total polyphenolics in the peel and 9.91 $\%$ of the pulp. Three quercetin glycosides and one kaempferol glycoside were found in the peel. The results obtained in this study will help to further understand the polyphenolic composition in peach and the roles of these compounds in health promoting physiological functions.

\section{Acknowledgments}

This work was supported by the Ministry of Education, Science and Technological Development of Republic of Serbia (172047 and 174007).

\section{References}

Addinsoft (2016). Data analysis and statistical solution for Microsoft Excel, Paris, France.

Alothman M, Bhat R, Karim AA (2009). Antioxidant capacity and phenolic content of selected tropical fruits from Malaysia, extracted with different solvents. Food Chemistry 115:785-788.

Benzil IF, Strain JJ (1999). Ferric reducing antioxidant power assay: direct measure of total antioxidant activity of biological fluids and modified version for simultaneous measurement of total antioxidant power and ascorbic acid concentration. Methods in Enzymology 299:15-27.

Brand-Williams W, Cuvelier M, Berset C (1995). Use of a free radical method to evaluate antioxidant activity. LWT- Food Science and Technology 28:25-30.

Cantin CM, Moreno MA, Gogorcena Y (2009). Evaluation of the antioxidant capacity, phenolic compounds, and vitamin $\mathrm{C}$ content of different peach and nectarine (Prumus persica L. Batsch) breeding progenies.Journal of Agricultural and Food Chemistry 57:45864592.

Cevallos-Casals DA, Byrne D, Okie WR, Cisneros-Zevallos L (2006). Selecting new peach and plum genotypes rich in phenolic compounds and enhanced functional properties. Food Chemistry 96:273-280.

Chang S, Tan K, Francel EN, Barrett DM (2000). Low-density lipoprotein antioxidant activity of phenolic compounds and polyphenol oxidase activity in selected Clingstone peach cultivars. Journal of Agricultural and Food Chemistry 48:147-151.

Concalves B, Landbo A-K, Knudsen D, Silva AP, Moutinho-Pereira J, Rosa E, Mayer AS (2004). Effect of ripeness and postharvest storage on the phenolic profiles of cherries (Prunus avium L. Journal of Agricultural and Food Chemistry 52:523-530. 
182

Dorman HJD, Peltoketo A, Hiltunen R, Tikkanen MJ (2003). Characterization of the antioxidant properties of de-odourized aqueous extracts from selected Lamiaceae herbs. Food Chemistry 83:255-262.

Gong Y, Liu X, Xu WH, Yuan F, Gao YX (2012). Investigation into the antioxidant activity and chemical composition of alcoholic extracts from defatted marigold (Tagetes erecta L.) residue. Fitoterapia 83:481-489.

Gorinstein S, Martin-Belloso O, Lojek A, Čiž M, Soliva-Fortuny R, Park Y-S, Caspi A, Libman I, Trakhtenberoj S (2002). Comparative content of some phytochemicals in Spanish apples, peaches and pears. Journal of the Science of Food and Agriculture 82:1166-1170.

Gougoulias N, Mashev N (2006). Antioxidant effects and polyphenol content in some Greek wines from Macedonia and Thrace. Oxidation Communications 29:585-594.

Guo C, Yang J, Wei J, Li Y, Xu J, Jiang Y (2003). Antioxidant activities of peel, pulp and seed fractions of common fruits as determined by FRAP assay. Nutrition Research 23:1719-1726.

Hamauzu Y, Takanori I, Kume M, Hiramatsu K (2006). Antioxidant and antiulcerative properties of phenolics from Chinese quince, quince, and apple fruits. Journal of Agricultural and Food Chemistry 54:765-722.

Kajdžanoska M, Petreska J, Stefova M (2011). Comparison of different extraction solvent mixtures for characterization of phenolic compounds in strawberries. Journal of Agricultural and Food Chemistry 59:5272-5278.

Lee KW, Kim YJ, Kim DO, Lee CY (2003). Major phenolics in apple and their contribution to the total antioxidant capacity. Journal of Agricultural and Food Chemistry 51:6516-6520.

Lim YY, Quah EPL (2007). Antioxidant properties of different cultivars of Portulaca oleracea. Food Chemistry 103:734740.

Malenčić DJ, Popović M, Stajner D, Mimica-Dukić N, Boža P, Mathe I (2002). Screening for antioxidant properties of Salvia nemorosa $\mathrm{L}$. and Salviaglutinosa L. Oxidation Communications 25:613-619.

Manzoor M, Anwar F, Mahmood Z, Rashid M, Ashraf M (2012a). Variation in minerals, phenolics and antioxidant activity of peel and pulp of different varieties of peach (Prunus persica L.) fruit from Pakistan. Molecules 17:6491-6506.

Manzoor M, Anwar F, Saar N, Ashraf M (2012b). Variations of antioxidant characteristics and mineral contents in pulp and peel of different apple (Malus domestica Borkh.) cultivars from Pakistan. Molecules 17:390-407.

Mattila P, Hellström J, Törrönen R (2006). Phenolic acids in berries, fruits, and beverages. Journal of Agricultural and Food Chemistry 54:7193-7199.

Mitic SS, Stojanovic BT, Pavlovic AN, Mitic MN, Stojkovic MB (2013). The phenol content, antioxidant activity and metal composition of the Serbian vineyard peach. Revue Roumaine de Chimie 58:533-541.

Mohdaly AA, Sarhan MA, Smetanska I, Mahmoud A (2010). Antioxidant properties of various solvent extracts of potato peel, sugar peel pulp and sesame cake. Journal of the Science of Food and Agriculture 90:218-226.
Montevecchi G, Simone GV, Masino F, Bignami C, Antonelli A (2012). Physical and chemical characterization of Pescabivona, a Sicilian white flesh peach cultivar (Prunus persica L. Batsch). Food Research International 45:123-131.

Orazem P, Stamper F, Hudina M (2011). Fruit quality of Redhaven and Royal Glory peach cultivars on seven different rootstocks. Journal of Agricultural and Food Chemistry 59:93949401.

Ozgen M, Resse RN, Tulio AZJ, Scheerens JC, Miller AR (2006). Modified 2,2-azino-bis-3-ethylbenzothiazoline-6-sulfonic acid (ABTS) method measure antioxidant capacity of selected small fruits and comparison to ferric reducing antioxidant power (FRAP) and 2,2'-diphenyl-1-picrylhydrazyl (DPPH) methods. Journal of Agricultural and Food Chemistry 54:1151-1157.

Reig G, Iglesias I, Gatius F, Alegre S (2013). Antioxidant capacity, quality, and anthocyanin and nutrient content of several peach cultivars (Prunus persica L. Batsch) grown in Spain. Journal of Agricultural and Food Chemistry 61:6344-6357.

Remorini D, Tavarini S, Deg'Innocenti E, Loreti F, Massai R, Guidi L (2008). Effect of rootstocks and harvesting time on the nutritional quality of peel and flesh of peach fruit. Food Chemistry 110:361-367.

Rimm EB, Ascherio A, Giovannucci E, Spiegalman D, Stamfer M, Willett W (1996).Vegetable, fruit and cereal fiber intake and risk of coronary heart disease among men. The Journal of the American Medical Association 275:447-451.

Scordino M, Sabotano L, Muratole A, Belligno A, Gagliano G (2012). Phenolic characterization of Sicilian yellow flesh peach (Prunus persica L.) cultivars of different ripening stages. Journal of Food Quality 35:255-262.

Silva BM, Andrade PB, Ferreres F, Domingues AL, Seabra RM, Ferreira MA (2002). Phenolic profile of quince fruit (Cydonia oblonga Miller) (Pulp and Peel). Journal of Agricultural and Food Chemistry 50:4615-4618.

Stratil P, Klejdus B, Kuban V (2006). Determination of phenolic compounds and their antioxidant activity in fruits and cereals. Talanta 7:1741-1751.

Tomas-Barberan FA, Gill MI, Cremin P, Waterhouse LA, Hess Pierce B, Kader AA (2001). HCLP-DAD-ESIM analysis of phenolic compounds in nectarines, peaches, and plums. Journal of Agricultural and Food Chemistry 49:4748-4760.

Vizzoto M, Cisneros-Zevallos L, Byrne DH (2007). Large variation found in the phytochemical and antioxidant activity of peach and plum germplasm. Journal of the American Society for Horticultural Science 132:334340.

Witzum J, Steinberg D (1991). Role of oxidized low density lipoprotein in artherogenesis. Journal of Clinical Investigation 88:1785-1792.

Yu L, Haley S, Perret J, Harris M, Wilson J, Qian M (2012). Free radical scavenging properties of wheat extracts. Journal of Agricultural and Food Chemistry 50:1619-1624. 